\title{
PROYECCIONES DEL ARCHIVO LATINOAMERICANO EN LA REVISTA ANCLAJES
}

\author{
Irina Garbatzky \\ Instituto de Estudios Críticos en Humanidades, IECH \\ Universidad Nacional de Rosario \\ Consejo Nacional de Investigaciones Científicas y Técnicas, CONICET \\ Argentina \\ garbatzky@iech-conicet.gob.ar \\ ORCID: 0000-0002-I349-0585
}

Fecha de recepción. 16/06/2021 | Fecha de aceptación: 25/06/2021

Resumen: A lo largo de sus números la revista Anclajes se presenta como el espacio idóneo para la actualización de la agenda sobre los estudios literarios latinoamericanos y el archivo. En sus distintas facetas vinculadas con el canon, la tradición y la biblioteca, atravesadas por su heterogeneidad constitutiva en torno a materialidades, tecnologías y soportes, el archivo latinoamericano se ha constituido como una problemática central y una perspectiva crítica. Se ordenan sus inflexiones a lo largo de la revista y se analiza la vinculación del problema teórico con la óptica de los estudios latinoamericanos.

Palabras clave: archivo latinoamericano; producción académica; revistas académicas; canon; heteronomía.

\section{Projections of the Latin American archive in the journal Anclajes}

Abstract:Throughout its issues, the journal Anclajes is presented as the ideal space for updating the agenda on Latin American literary studies and the archive. In its different facets, linked to the canon, tradition, the library, and characterized by its constitutive heterogeneity of materialities, technologies and supports, the Latin American archive has become a central problem and a critical perspective. This article traces its development throughout the history of the journal and analyzes the connection between the theoretical framework and the Latin American studies field.

Keywords: Latin American archive; academic production; academic journals; canon; heteronomy.

\section{Projeçóes do arquivo latino-americano na revista Anclajes}

Resumo:Ao longo de suas edições, a revista Anclajes se apresenta como o espaço ideal para a atualização da agenda dos estudos literários latino-americanos e do arquivo. Em 
suas diferentes facetas, vinculadas ao cânone, à tradição e à biblioteca percorrida por sua heterogeneidade constitutiva em torno de materialidades, tecnologias e suportes, o arquivo latino-americano tornou-se um problema central e uma perspectiva crítica. Suas inflexões são ordenadas ao longo da revista e é analisada a conexão do problema teórico com a perspectiva dos estudos latino-americanos.

Palavras-chave: arquivo latino-americano; produção acadêmica; revistas acadêmicas; canone; heteronomia.

a revista Anclajes cumple veinticinco años. Ello es motivo de celebración por varias razones; entre otras, por el valor productivo que puede encontrarse sostenidamente a lo largo de sus números y las consecuencias positivas que esto supone para los estudios literarios latinoamericanos, el campo de conocimiento general de las Humanidades y la constitución de redes académicas.

Si al día de hoy podemos decir que el archivo constituye en sí mismo una perspectiva crítica, esto ha sido producto del crecimiento, en calidad y cantidad, de las investigaciones en un conjunto de aportes teóricos que comprenden sus problemáticas en múltiples dimensiones. Archivo se denomina a la reunión y domiciliación de un acervo documental, a su lugar de emplazamiento, pero también a la posibilidad de visibilizar y producir, a partir de un sistema determinado, una serie discursiva, una operación de lectura. En estos años, además de la ingente producción de nuevas colecciones y proyectos, los estudios sobre archivo han abarcado diferentes asuntos, como la constitución de archivos de escritores, los alcances y reformulaciones en los estudios biográficos, las transformaciones del canon. Asimismo, desde los estudios propiciados por las teorías del archivo se han abierto nuevas zonas de investigación, como aquellas referidas a las identidades subalternas en el archivo colonial o los límites que rodean al documentalismo y la historiografía. A su vez, los restos, objetos y materialidades que desbordan la experiencia pero que ingresan en las poéticas latinoamericanas hacia el siglo XXI también se comprenden -desde una línea benjaminiana vinculada con la historia de las imágenes- en términos de archivo. En su característica heterogeneidad de fuentes y soportes, el archivo latinoamericano viene siendo un punto de vista central para los estudios literarios y culturales, tanto en lo concerniente a las temáticas de sus producciones como a la demanda de nuevas metodologías.

El trayecto por Anclajes da cuenta de la revista como un espacio idóneo para la actualización de esta zona de reflexiones. A través de sus números podemos observar los avances de esta cuestión en la inclusión de determinadas problemáticas y ordenarla en distintas líneas que recorren la publicación: aquellas que indagan las lecturas y relecturas del archivo y del canon latinoamericano, las que refieren sus intertextualidades y recepciones y las que cuestionan sus límites a 
partir de los bordes de la letra y el ingreso, en su revisión, de tecnologías audiovisuales o performático-corporales.

Una serie de artículos que exploran las redimensiones del canon son particularmente interesantes para reflexionar acerca de las formas en que la teoría archivística dialoga con las singularidades de la literatura latinoamericana, ese "corpus orgánico", como lo había referido Ángel Rama, en permanente intercambio entre la letra y sus ámbitos de actuación cultural. Aportes como el de Carla Fumagalli (2018) respecto de la exhumación de nuevos documentos situados por fuera de la Obra completa de Sor Juana Inés de la Cruz, o el de Dardo Scavino (2014), quien discute con las miradas de Octavio Paz y de Serge Gruzinsky sobre la monja mexicana en lo concerniente a su pluralismo liberal o mestizaje cultural, permiten reflexionar tanto sobre la noción misma de archivo como sobre la constitución del corpus canónico, sus momentos de reapertura o estabilización. Cabe en este punto recordar la intervención de Susana Zanetti en un artículo publicado en el año 2000 en donde volvía sobre la discusión trazada por Harold Bloom para reflexionar sobre el valor del canon latinoamericano. Decía allí: "Por el canon pasa un foco de irradiación que ilumina el tejido de una temporalidad compleja donde se refractan relecturas, intertextualidades, linajes y polémicas, así como un universo simbólico e imaginarios que sustentan nuestras concepciones estéticas" (230). Lejos de una lista de obras maestras o de las referencias a una institucionalización apaciguadora y definitiva $-\mathrm{y}$ lejos, por lo tanto, de la solidez o cerrazón del "canon occidental"-, Zanetti planteaba de qué modo el canon latinoamericano se presenta como un conjunto inestable y móvil con procesos de constitución mucho más recientes y periféricos, y fundamentalmente conformado por las operaciones de lectura y relectura de los escritores y de la crítica. Las contribuciones publicadas en Anclajes continúan esa agenda, cuya premisa sugiere que sería imposible pensar al canon latinoamericano desde una óptica que no incorpore la naturaleza constelar y abierta del archivo. El título del artículo de Facundo Ruiz (2013) resulta elocuente en ese sentido: "Barroco, esta obra, aquel concepto, ese período". Según el autor se trata de pensar no ya qué es el barroco sino de qué es capaz, cuáles son sus potencialidades. Son también congruentes con esta perspectiva los trabajos que indagan en torno de autores canónicos a través de nuevos enfoques, -por ejemplo, las formas que adoptó José Martí, en tanto traductor de la modernidad, para difundir en Hispanoamérica el Trascendentalismo, como señala María Fernanda Pampín (2012), o bien para entender los procesos inmigratorios en Estados Unidos, como estudia Ariela Schnirmajer (2011).

Finalmente, otro segmento que se acerca a esta línea de revisitación canónica tendría que ver con las indagaciones en sus apropiaciones literarias y proyecciones. Hacia allí se orientó puntualmente el dossier que coordinamos con Julieta Viú Adagio, principalmente en el cotejo de dos finales de siglo: "El archivo de fin de siglo XIX en la literatura latinoamericana contemporánea" (2021). De ese dossier, resulta importante destacar, en relación con lo que aquí planteo, el ar- 
tículo de Marcela Zanin: "Llamado a Julián del Casal. La vida del poeta en José Lezama Lima y Antonio José Ponte". Allí la autora se pregunta, en términos del don y la filiación, cuál es el legado de Julián del Casal para los escritores cubanos del siglo XX, cuándo y cómo llega Casal a ser un ideal de poeta para otros poetas, especialmente para Ponte, después de un tejido de interpretaciones atravesado claramente por Orígenes.

En síntesis, en los momentos que acabo de citar, como en otros de Anclajes, las figuras del canon diseñan esa dimensión proyectiva sugerida por Zanetti. El canon contempla y anuda problemáticas cruciales de la cultura latinoamericana, como la lectura y la intervención crítica y las inflexiones políticas de cada caso. El canon se abre, se reinstituye o se re-serializa según las inquietudes de su presente.

Una siguiente línea que refiere al archivo literario latinoamericano puede trazarse en los artículos que analizan su relación con otras literaturas, en términos de traducción, traslación o intertextualidad. Desde abordajes ligados fuertemente con el aparato conceptual de Gérard Genette, como el de Amalia Iniesta Cámara (1998) acerca de la novela histórica de Napoleón Baccino Ponce de León, hasta el análisis de Silvana López (2012) sobre las reescrituras de Héctor Libertella de los viajes de Antonio Pigafetta, la revisión realizada por Gloria Stolk acerca de Teresa de la Parra en el trabajo de Carmen Victoria Vivas Lacour (2009) o la hipótesis de Ludmila Barbero (2018) en torno a los cuentos de hadas reescritos por Alejandra Pizarnik, la línea intertextual y la noción de reescritura se mantiene vigente.

Otra reagrupación se observa en los abordajes vinculados con las revisiones de la biblioteca, en lengua propia y en lenguas extranjeras, que tienden a señalar los usos y las posiciones adoptadas como estrategias en un debate específico. María Virginia González (2015) en su análisis sobre Estatuas de sal. Cuentistas cubanas contemporáneas, la antología realizada por Marilyn Bobes y Mirta Yánez, recupera en su epígrafe dos preguntas de Arcadio Díaz Quiñones que resultan vectores no sólo de su artículo sino del archivo como perspectiva. "¿Qué significa pertenecer a una tradición? ¿Cuál será el punto de apoyo para sostener su autoridad?" (24), subraya González, y con ello pone en escena la pregunta del crítico puertorriqueño respecto de en qué momento se da inicio a una serie y qué objetivos buscan los intelectuales al inventar la propia genealogía. "La tradición", observa la autora, "no aparece como algo que se posee o se hereda sino que es necesario ir en su búsqueda y, en este movimiento constructivo, los escritores se reinventan mediante un trabajo poético e intelectual" (25). En el caso de Yáñez y Bobes, durante el Período especial, su selección tiene como efecto la difusión de escritoras no visibilizadas, a la vez del armado de una tradición, en un momento de revisión del canon literario en Cuba. Otro artículo interesante para este dilema es el de Judith Podlubne (2005), quien sitúa en la revista Sur las diferentes semblanzas y abordajes de G. K. Chesterton y de Franz Kafka realizadas por Jorge Luis Borges y Eduardo Mallea respectivamente, como intervenciones en un 
conflicto a media voz en torno al valor de la personalidad (o la impersonalidad) en la literatura. Los artículos de González y Podlubne configuran así dos momentos para pensar el problema del archivo como operación crítica e inventiva que los escritores y escritoras arman para su obra.

La tercera línea que observamos es aquella que recorre al archivo en sus límites disciplinares, a través de la tecnología, la corporalidad y la historiografía. Fernando Degiovanni en "Correspondencias sumergidas: latinoamericanismo, performance y archivo en Manuel Ugarte" (2020) elabora un nuevo archivo, o acaso uno menos recorrido: el de las conferencias performáticas realizadas por los intelectuales de finales del XIX y comienzos del XX. A partir de las formas de afectividad y convivio que supone la performance, Degiovanni analiza las giras emprendidas por Manuel Ugarte en los países de América Latina y Estados Unidos, en 1911 y 1913, como estrategias para convocar a una audiencia masiva y apelar a una política latinoamericanista utilizando esquemas alternativos a la dimensión letrada, ya trabajada por los modernistas. La conferencia como dispositivo extendido en notables ejemplos decimonónicos y el telegrama como tecnología que permitía comunicar con más rapidez e intensidad colaboraban a tal fin. De este modo, el libro que narra esta gira, El destino de un continente (1923), se configura como "un archivo performático que permite pensar otra genealogía del latinoamericanismo, anclada en nociones de cuerpo, tecnología y afecto" (137).

Se trata de observar que, en el avance de las investigaciones, otros soportes del archivo son explorados y puestos en relieve. Además del artículo de Degiovanni pueden citarse en este segmento los trabajos de Jorge Sala (2017) y de Nicolás Suárez (2018), en donde aparece la pregunta por los modos de la reescritura y el trasvase del teatro o la literatura al cine.

Por último, y no menos importante, cabe mencionar que recurrir al archivo también supone una indagación intermedial cuando se trata, bien de la novela histórica, bien de la historiografía como materialidad. Ello se estudia, por ejemplo, en el artículo de Jungwon Park (2013), acerca del uso del archivo historiográfico manicomial que traza Cristina Rivera Garza y asimismo en el artículo de Mariana Libertad Suárez (2013), sobre la novela biográfica La mujer del caudillo, de Nery Russo. El problema de la verdad y la dimensión del archivo como registro y documentación se posicionan, ya desde un género o desde la cuestión documental, en tanto dimensión heterogénea contra la cual la narrativa latinoamericana se configura. Esta cuestión formaba parte, según la hipótesis de Roberto González Echevarría en Mito y archivo, de los propios procesos de constitución de la novela moderna latinoamericana y casi como el fundamento mismo de su emergencia. Los artículos citados arriba, entre otros, activan esta relación, revisando sus alcances en la esfera heteronómica de la cultura latinoamericana.

Ciertamente, los trabajos que aquí mencioné son apenas anotaciones en el conjunto más amplio que publicó la revista Anclajes como contribuciones al problema del archivo a lo largo del tiempo. El dibujo que sus diferentes refe- 
rencias traza hablaría de las proyecciones de un problema en lo que concierne a los contenidos -el archivo y el canon, la tradición literaria, la biblioteca-, y a las formas y sus soportes -el archivo en su dimensión tecnológica.

El pensamiento sobre el archivo aparece como la trama detrás de cada una de estas contribuciones. $\mathrm{O}$ acaso sea al revés y podamos pensar que es la óptica de los problemas latinoamericanos la que permite el avance sobre las teorías del archivo. Anclajes ofrece las entradas para ambos puntos de vista.

\section{Referencias bibliográficas}

Barbero, Ludmila. "Belle comme un rêve de Pierre: La condesa sangrienta de Alejandra Pizarnik como reescritura de cuentos de hadas". Anclajes, vol. XXII, n ${ }^{\circ}$, enero-abril 2018, pp. 1-17, https://doi.org/10.19137/anclajes-2018-2211

Degiovanni, Fernando. "Correspondencias sumergidas: latinoamericanismo, performance y archivo en Manuel Ugarte". Anclajes, vol. XXIV, n. ${ }^{\circ} 3$, septiembre-diciembre 2020, pp. 137-153, https://doi.org/10.19137/anclajes2020-24310

Fumagalli, Carla Anabella. "Sor Juana Inés de la Cruz: articulaciones entre obra $\mathrm{y}$ archivo en los preliminares de sus ediciones originales". Anclajes, vol. XXII, n. ${ }^{\circ}$ 1, enero-abril 2018, pp. 37-53, https://doi.org/10.19137/anclajes-20182213

Garbatzky, Irina y Julieta Viú Adagio. "El archivo de fin de siglo XIX en la literatura latinoamericana contemporánea”. Anclajes, vol. XXV, n. ${ }^{\circ} 1$, enero-abril 2021, pp. 1-7, https://doi.org/10.19137/anclajes-2021-2511

González, María Victoria. "Estatuas de sal: urdimbres para una tra(d)ición de escritoras cubanas". Anclajes Vol. XIX, n. ${ }^{\circ} 2$, 2015, pp. 24-40, https://doi. org/10.19137/anclajes-2015-1923

González Echevarría, Roberto. Mito y archivo: Una teoría de la narrativa latinoamericana. México, Fondo de Cultura Económica, 2000.

Iniesta Cámara, Amalia. "El Nuevo Mundo en la crónica y en la fábula”. Anclajes Vol. II, n. ${ }^{\circ} 2,1998$, pp. 57-76.

López, Silvana. "Libertella escribe y reescribe el viaje de Magallanes". Anclajes Vol. XVI, n. ${ }^{\circ} 2$, 2012, pp. 39-58.

Pampín, María Fernanda. “Ese don raro de asir la música y el espíritu de las lenguas'. Los mecanismos implícitos en el proceso de traducción en la obra de José Martî". Anclajes Vol. XVI, n. ${ }^{\circ}$ 2, diciembre 2012, pp. 59-71.

Park, Jungwon. "Manicomio y locura: revolución dentro de la Revolución Mexicana en Nadie me verá llorar de Cristina Rivera Garza", Anclajes vol. XVII, n. 1, julio 2013, pp. 55-72, https://doi.org/10.19137/anclajes-2013-1714 
Podlubne, Judith. "Lecturas cruzadas en la revista Sur: Mallea y Borges sobre Kafka y Chesterton”. Anclajes, Vol. IX., n. ${ }^{\circ}$ 9, enero-diciembre 2005, pp. 119-139.

Ruiz, Facundo. "Barroco: esta obra, aquel concepto, ese período". Anclajes Vol. XVII, nº 1 , julio 2013, pp. 73-89, https://doi.org/10.19137/anclajes-20131715

Sala, Jorge. "Casarse con una viuda. El reñidero y la reescritura fílmica de éxitos teatrales en el nuevo cine argentino". Anclajes, vol. XXI, n 2, mayo-agosto 2017, pp. 59-75, https://doi.org/10.19137/anclajes-2017-2124

Scavino, Dardo. "Sor Juana Inés de la Cruz y el espejo de los enigmas". Anclajes Vol. XVIII, n. ${ }^{\circ}$ 1, julio 2014, pp. 27-45, https://doi.org/10.19137/anclajes2014-1813

Schnirmajer, Ariela. "Minorías sociales y heterogeneidad: José Martí y la inmigración europea”. Anclajes, Vol. XV, n.o 1, julio 2011, pp. 49-59.

Suárez, Mariana Libertad. "La patria titubeante: el envés de la Guerra de Independencia en La mujer del caudillo (1952), de Nery Russo". Anclajes Vol. XVII, n. ${ }^{\circ}$ 2, 2013, pp. 65-87, https://doi.org/10.19137/anclajes-20131725

Suárez, Nicolás. "La pampa en movimiento: figuraciones del paisaje del Martín Fierro de José Hernández al filme Nobleza gaucha". Anclajes, vol. XXII, n. ${ }^{\circ}$ 1, enero-abril 2018, pp. 73-94, https://doi.org/10.19137/anclajes-2018-2215

Vivas Lacour, Carmen Victoria. "Amargo el fondo (1957). El diálogo con la tradición femenina en la literatura: distancias y cercanías con Teresa De la Parra”. Anclajes, Vol. XIII, n. ${ }^{\circ} 13$, enero-diciembre 2009, pp. 165-175.

Zanetti, Susana. "¿Un canon necesario? acerca del canon literario latinoamericano", Voz y escritura n. ${ }^{\circ}$ 10, 2000, pp. 227-241.

Zanin, Marcela. "Llamado a Julián del Casal. La vida del poeta en José Lezama Lima y Antonio José Ponte", Anclajes vol. XXV, n. ${ }^{\circ}$ 1, enero-abril 2021, pp. 103-112, https://doi.org/10.19137/anclajes-2021-2518 